\title{
Chemometric techniques in distribution, characterisation and source apportionment of polycyclic aromatic hydrocarbons (PAHS) in aquaculture sediments in Malaysia.
}

\begin{abstract}
This study investigated polycyclic aromatic hydrocarbons (PAHs) pollution in surface sediments within aquaculture areas in Peninsular Malaysia using chemometric techniques, forensics and univariate methods. The samples were analysed using soxhlet extraction, silica gel column clean-up and gas chromatography mass spectrometry. The total PAH concentrations ranged from 20 to $1841 \mathrm{ng} / \mathrm{g}$ with a mean of $363 \mathrm{ng} / \mathrm{g} \mathrm{dw}$. The application of chemometric techniques enabled clustering and discrimination of the aquaculture sediments into four groups according to the contamination levels. A combination of chemometric and molecular indices was used to identify the sources of PAHs, which could be attributed to vehicle emissions, oil combustion and biomass combustion. Source apportionment using absolute principle component scores-multiple linear regression showed that the main sources of PAHs are vehicle emissions 54\%, oil 37\% and biomass combustion 9\%. Land-based pollution from vehicle emissions is the predominant contributor of PAHs in the aquaculture sediments of Peninsular Malaysia.
\end{abstract}

Keyword: PAHs; Chemometric; Aquaculture; Source apportionment; Surface sediment. 